\title{
NDEI-BASED MAPPING OF LAND SURFACE CHANGES
}

\author{
Victor Angulo Morales ${ }^{1, *}$, Jorge Rodríguez Galvis ${ }^{2}$, Elvis Gaona García ${ }^{1}$, Ivan Lizarazo Salcedo ${ }^{2}$ \\ ${ }^{1}$ Facultad de Ingeniería, Universidad Distrital Francisco Jose de Caldas, Bogotá, Colombia \\ ${ }^{2}$ Facultad de Ciencias Agrarias, Universidad Nacional de Colombia, Bogotá, Colombia
}

KEY WORDS: NDEI, UAV, Remote sensing, Land surface changes, DEM

\begin{abstract}
:
Topography measurements of land surface elevation changes are essential for geomorphological studies and research on natural hazards. However, conventional topography and remote sensing methods pose several challenges. Fieldwork in remote areas could be insecure or be hard to conduct due to physical barriers. Remote sensing satellite images, in turn, may lack the temporal resolution for monitoring topography changes or be covered by clouds and shadows that reduce their usefulness. Unmanned Aerial Vehicles (UAV) provide high-resolution imagery from remote areas and may give a greater insight into land surface changes. Previous studies have demonstrated the potential of the Normalized Difference Elevation Index (NDEI), derived from UAV surveys, to map changes in topography in different environments, including a quarry zone of sand mines in Colombia, and in the North Pole Ice Cap. As the NDEI is a metric capable to reveal topography disturbances, it could be exploited for rapid assessments of mass movements occurrence. For this research, a fine temporal resolution dataset of monthly NDEI values were used to explore their utility as a mass wasting identification technique. NDEI was used to map changes in the land surface in a quarry zone affected by landslides and mudflows. NDEI values were obtained from the multi-temporal analysis of digital surface models generated from UAV images and processed using Structure from motion (SfM) techniques. Main components of the proposed method are: (i)UAVbased imagery data capture, (ii)data processing using SfM techniques, (iii)NDEI calculation, and (iv)mass movement identification. Results illustrate the feasibility of using UAV-based imagery data to increase the accuracy of land changes information and produce rapid assessments of mass movements occurrence. Results show that the NDEI approach may increase the accuracy of land surface changes assessment and mapping, as well as enable the design of new methodologies to identify natural hazards and risks.
\end{abstract}

\section{INTRODUCTION}

The latest advances in remote sensing technologies have concluded to be efficient in topographic studies related to land surface changes, geomorphology, monitoring and control for disaster prevention. (Erdelj, Natalizio, 2016). The United Nations Office for Disaster Risk Reduction (UNDRR) use tools and images for fieldwork information support, where the principal scope is monitoring and reviewing progress towards disaster risk reduction and resilience building (Wannous, Velasquez, 2017) Some researches have shown that using multitemporal monitoring it is possible to observe the behavior land surface (Hill et al., 1995), (Stow et al., 1996). Land surface monitoring information is useful for sustainable land management, reduce landslide risks and to track land surface behavior due to natural transformations or land use processes such as agriculture (Gessesse et al., 2015).

The most common remote sensing techniques used to monitor the land surface are satellite images (Chapin et al., 2005), (Borrelli et al., 2017). However, satellite studies have been developed with low resolutions ( 2 meters/pixel to 50 meters/pixel) to detect small changes in the models, also sampling and analysis are done in periods of up to one image for every 3 years. The advantage of using Unmanned Aerial Vehicles (UAV) is the multi-temporal sampling of research areas and acquisition of spatial information and digital elevation models, obtained from spectral and spatial analysis.

One of the most used technologies of the last years is the Unmanned Aerial Vehicles, the UAV began their development in

\footnotetext{
*vdangulom@correo.udistrital.edu.co
}

the military practice, to later carry out functions in civil environments and their prompt incorporation to carry out measures in mineral exploration (Muchiri, Kimathi, 2016). In 2004, $2 \%$ of UAVs in the United States were used in civil operation (Newcome, 2004), however, the development and impact of these technologies in different fields of science have expanded their use. The report of the International Association for Unmanned Aerial Vehicles (AUVSI), in 2013, show the economic impact of the use of unmanned aerial vehicles in the United States, the report shows that the benefit will be 82 billion dollars and more than 100,000 jobs will be created in the next years (Jenkins, Vasigh, 2013).

At the present, one of the main applications of UAVs is the processing of information captured by UAVs with optical sensors to obtain Digital Elevation Models (DEM) and orthophoto mosaic (Uysal et al., 2015), (Ruzgienè et al., 2015), (Agüera-Vega et al., 2016). The use of UAVs in topographic measurements has intensified due to advances in engineering and cost reduction (Cook, 2017). Low-cost sensor technology installed in $\mathrm{UAV}$ s in recent years has allowed this remote sensing technology to be used in surveying and topographic applications (Clapuyt et al., 2016), analyze natural behaviors in land surface changes as erosion (Bergstrom et al., 2019), and methodologies for topography reconstruction (Rossi et al., 2017).

Low-cost UAVs use optical sensors that acquire information with high spatial resolution, the sensors are low-cost cameras, which are used to produce information that is useful for making quick decisions (Fugazza et al., 2018). Currently, in some areas at risk of mass movement, monitoring is carried out using topography fieldwork techniques, where the people who capture information are at high risk due to the conditions of the terrain, 
also these methodologies require a high time to perform work in areas of difficult access. The advantage of using UAV is the reduction of risk for the operator and the fieldwork is significantly reduced.

The mapping of land surface changes with remote sensing includes different techniques, the main methods are: (i) mapping of changes based on changes in spectral information, (ii) mapping of changes based on changes in planimetric (2D) information, and (iii) mapping of changes based on elevation changes. Studies have used digital elevation models to mapping changes in land surface to monitoring erosion, deposition, changes in volume and geomorphological behavior based in high-resolution model. (James et al., 2012). When sampling in different periods of time, temporal analysis of the evolution of the digital elevation models and the changes in the different periods studied can be carried out. Previous studies have demonstrated the potential of the Normalized Difference Elevation Index (NDEI), based on images with UAVs, to identify changes in land surface elevation in different environments (Lizarazo et al., 2017). NDEI index obtained from UAV-based imagery, is used to monitoring hollow formations caused by the collapse of ice in the glacier and to calculate land surface changes over three time periods (LIULeibao, 2019).

The purpose of this paper is a novel technique that allows mapping changes in the land surface applied for the identification of mass movements. The representation of the uncertainty of the change in land surface elevation is done through the NDEI index. The method proposed in this article is: (i)UAV-based imagery data capture, (ii)data processing using SfM techniques, (iii)NDEI calculation, and (iv)mass movement identification.

This article is organized: First, the description of the study area used in this article, then a description of the method used, data capture, and processing, then a description of the NDEI index and its application for the identification of mass movements, then the results and conclusions are presented.

\section{DATA AND METHODS}

The method proposed in this article uses de index NDEI from UAV-based imagery images and low-cost sensors to map changes in land surface applied for the identification of massive movements. The method and data for identification of elevation changes is: (i) Study Area, (ii) data capture, (iii) data processing, (iv) NDEI, (v) identification of massive movements.

\subsection{Study area}

The study area is a sand mine of approximately $650 \mathrm{Ha}$, located in the zone of Zipaquira, Cundinamarca (Colombia). The area is located 42 kilometers northwest of the city of Bogota. The study area is at an approximate height of 2700 metres above sea level. With an approximate area of $10 \mathrm{ha}$, the study area selected in this paper is a material storage area of approximately 6000 sq.m. Figure 1.

\subsection{Data capture}

There were 5 UAV-missions to capture images during the months of January, February, March, April and May 2016. Flights were performed at 70 meters altitude on photogrammetric flight routes programmed using the ground control station software. The photogrammetric missions were carried out with
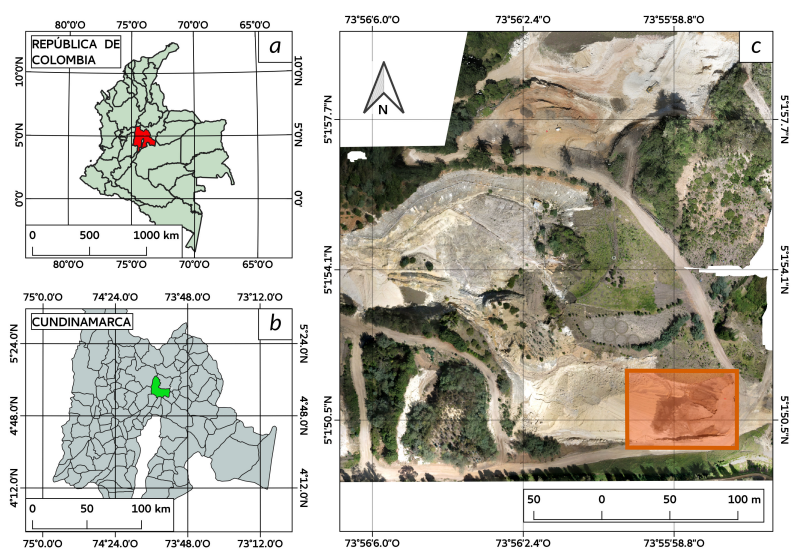

Figure 1. Location of study area, a quarry zone in Zipaquira, Cundinamarca (Colombia): (a) Colombia's departments (light green colour), Cundinamarca (red colour); (b) Cundinamarca's municipalities (light grey colour), Zipaquira municipality (green colour); (c) Deposit zone No. 5 is highlighted in orange colour.

a hexacopter Tarot 680PRO Figure 2a, with a low cost camera Canon S110 to obtain images with approximately $4 \mathrm{~cm}$ per pixel. The time of each flight was approximately 8 minutes.

In order to obtain high precision Digital Elevation Models, a total of 10 ground control points (GCP), raised with the total station OS-105 were located in the field. These points were marked with white and red cross lenses so that they were easily identifiable in the images Figure $2 b$.

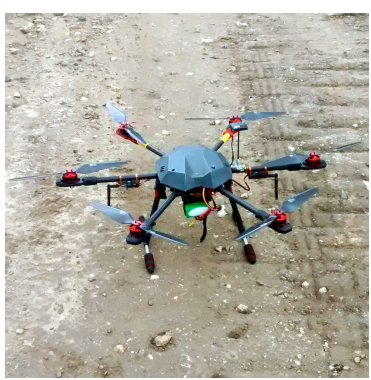

(a)

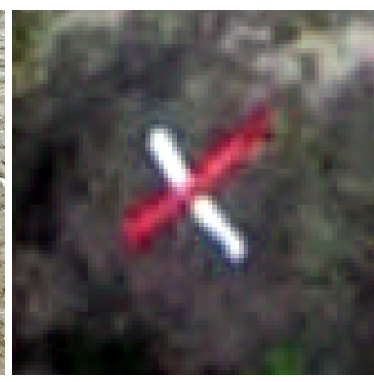

(b)
Figure 2. UAV used and markers for signalling GCP. (a) Hexacopter Tarot 680 PRO; (b) Marker in the form of a cross to mark the GCPs.

\subsection{Data processing}

In this stage, the photogrammetric adjustment of the images captured with the unmanned aerial vehicle is made, the software used to make this adjustment is Agisoft Photoscan, this software searches for similar points by analyzing all the images captured. The algorithm used to make this photogrammetric adjustment is the SIFT adjustment function for machine vision, likewise uses binary descriptors to facilitate the work of the processor and match the key points of each image with its adjacent. Figure 3.

The software uses UAV positioning sensors and ground control points to reconstruct the exact position and orientation of the optical sensor for each image acquired during the flight 


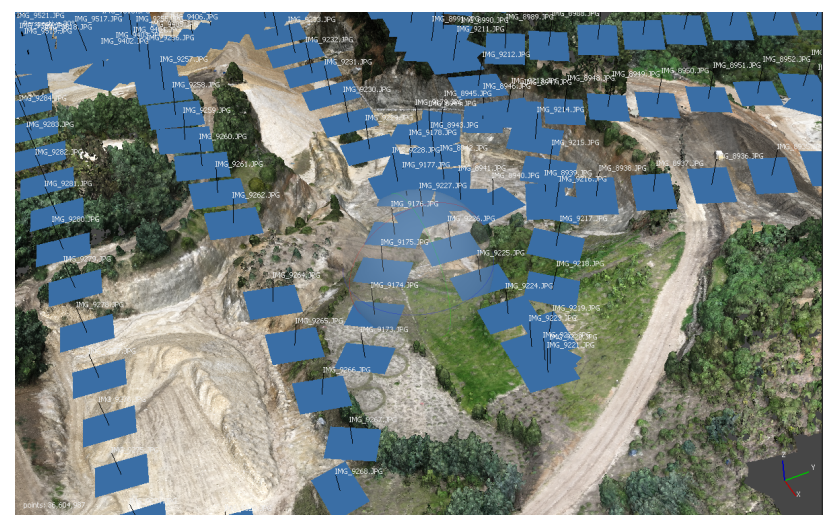

Figure 3. Photogrammetric adjustment

of the study area. Based on the alignment of the images, the coincident points are calculated with their coordinates in the MAGNA-SIRGAS reference system, with each point interpolation is made to form an irregular triangular network and a dense point cloud with positioning attributes and color value captured by the optical sensor. Once this process is completed, two Raster type products can be generated, the first is an Orthomosaic model and the second is a Digital Elevation Model, Figure 4.

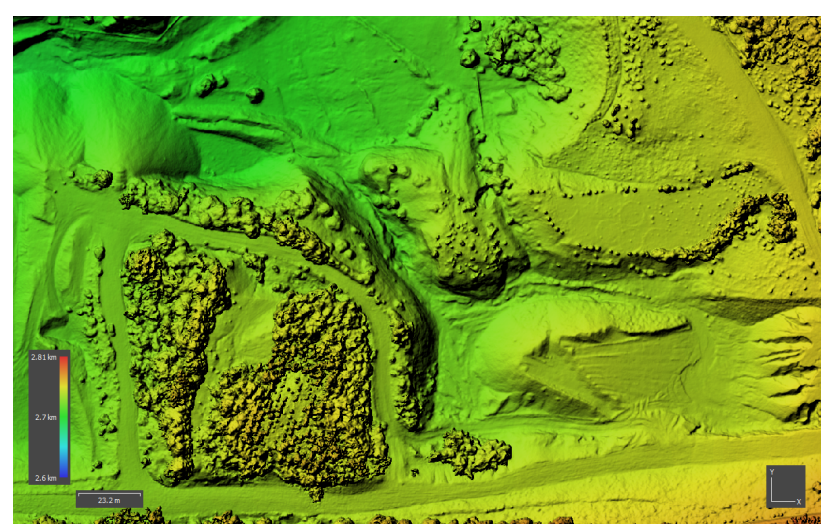

Figure 4. Digital elevation model

\subsection{NDEI: Normalized Difference Elevation Index}

Normalized Difference Elevation Index, is a tool that can be used to identify and quantify patterns of spatial change from images obtained with unmanned aerial vehicles. Two digital elevation models are calculated in a different time period, the index can be calculated by generating a spatially distributed highresolution surface model that identifies the elevation changes between the second period and the first period. NDEI definition is, Equation 1:

$$
N D E I_{t 21}=\frac{D E M_{t 2}-D E M_{t 1}}{D E M_{t 2}+D E M_{t 1}}
$$

where

$D E M=$ Digital elevation model's value

$D E M_{t 1}=$ Value of the early $D E M$

$D E M_{t 2}=$ Value of the later $D E M$

\subsection{Mass movement identification}

The results of the NDEI index between two time periods represent the decrease in elevation with values less than 0 , and the increase in elevation with values greater than 0 . These variations are caused by erosion, deposition, collapse, etc. The identification of the mass movement using the NDEI index can be made from the analysis of the data obtained between -1 and 1 . Figure 5, shows the calculated NDEI index of the study area, the red line is the selection of a terrain profile.

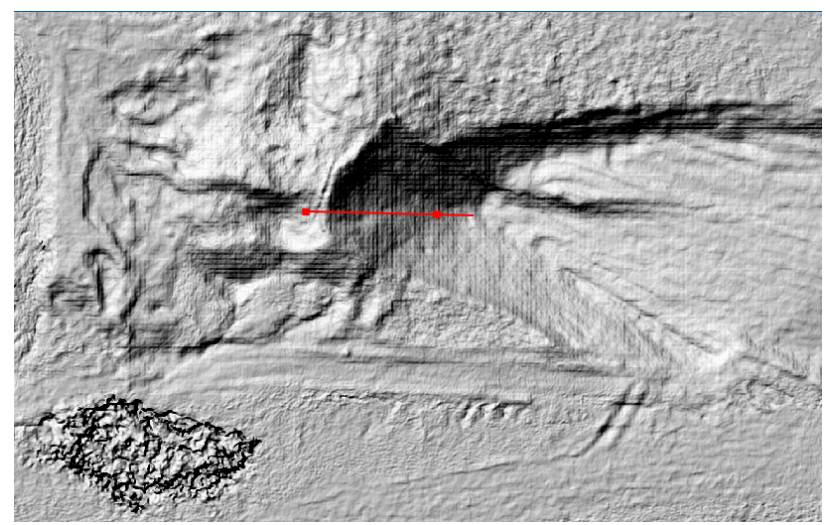

Figure 5. NDEI index

The analysis of the terrain profile and the data obtained allow the identification of zones of mass movements, Figure 6, shows the NDEI index data, the values greater than 0 correspond to an identified area where the elevation is increased between the periods $t 2 \mathrm{y} t 1$, and the negative values correspond to an identified area where a decrease in elevation was performed between assessment periods.

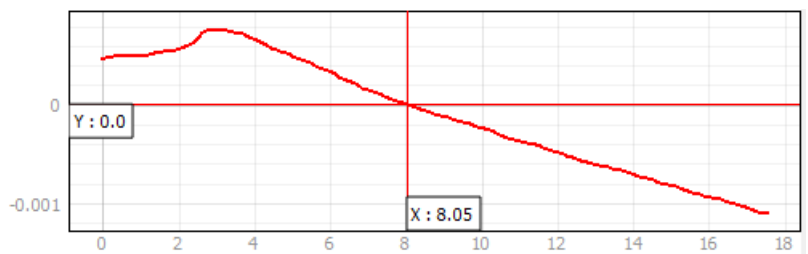

Figure 6. NDEI Profile

\subsection{Mapping mass movement zones}

The proposed method makes it possible to identify areas affected by the decrease in material, in some cases due to causes such as the runoff. The mapping mass movement zones of runoff areas was carried out by applying a threshold technique to the NDEI index, which limits were established for the detection of areas of decrease Equation 2.

$$
S(x, y)= \begin{cases}0 & \text { if } \operatorname{NDEI}(x, y)>-0.00015 \\ 1 & \text { if } \operatorname{NDEI}(x, y)<=-0.00015\end{cases}
$$

\section{RESULTS}

Figure 7 shows the DEMs obtained for the 5 dates: (a) January; (b) February; (c) March; (d) April; and (e) May. While it is possible to observe some large differences between periods at 
a glance, identifying precise zones of change is a complicated task from the DEMs alone. The greatest change detectable with the naked eye occurs between the months of March and April, this change occurs due to the beginning of the rainy season in the study area.
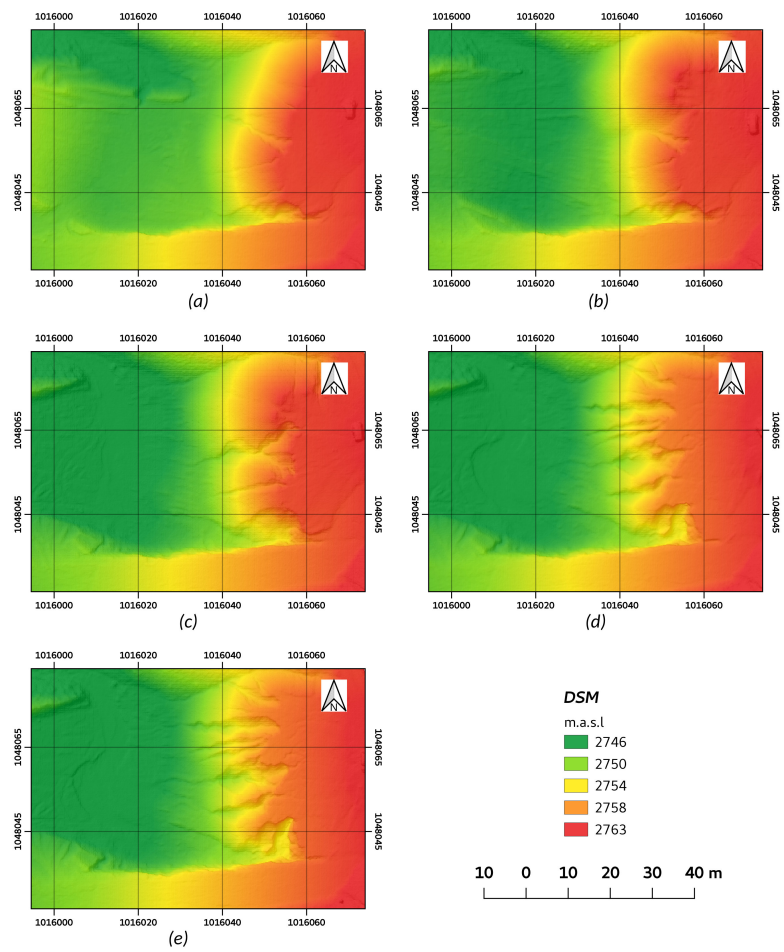

Figure 7. DEMs obtained for all months under study: (a) January; (b) February; (c) March; (d) April; and (e) May.

Figure 8, shows the orthomosaics of the study area obtained for the dates of capture: (a) January; (b) February; (c) March; (d) April; and (e) May. In the orthomosaics are clearly observable the changes that occur in the land surface through time between the first 4 months: January, February, March, and April. However, changes in the land surface between April and May are not evident to the naked eye. In the orthomosaics it is observed that the notable changes begin to occur from the month of March, due to the beginning of the rainy season, cracks begin to be created that are increasing in size due to the superficial runoff caused by intense rains.

Figure 9, shows the NDEI index calculated for the 5 months: (a) January-February; (b) February-March; (c) March-April; and (d) April-May. Green indicates areas of material accumulation, red indicates areas of material loss, and yellow indicates areas of minimal or no change. NDEI of January and February shows two large areas of deposition and loss of material, these changes correspond to movements of material made by the company of the mine, in this case no cracks are observed in the index. NDEI of the February-March periods shows two areas of material loss, one large area has its origin in the normal activities of the mine while for the other area it is evident that the runoff produced by the rains has generated several deep cracks in the terrain. The major changes in the terrain produced by the rain are observed in the months of March and April, while the change produced by the mine operations was small, the change produced by the runoff was remarkable. The cracks that began to form at the end of March become deeper causing instability and causing a large mass of adjacent soil to sink a few centimeters. In con-
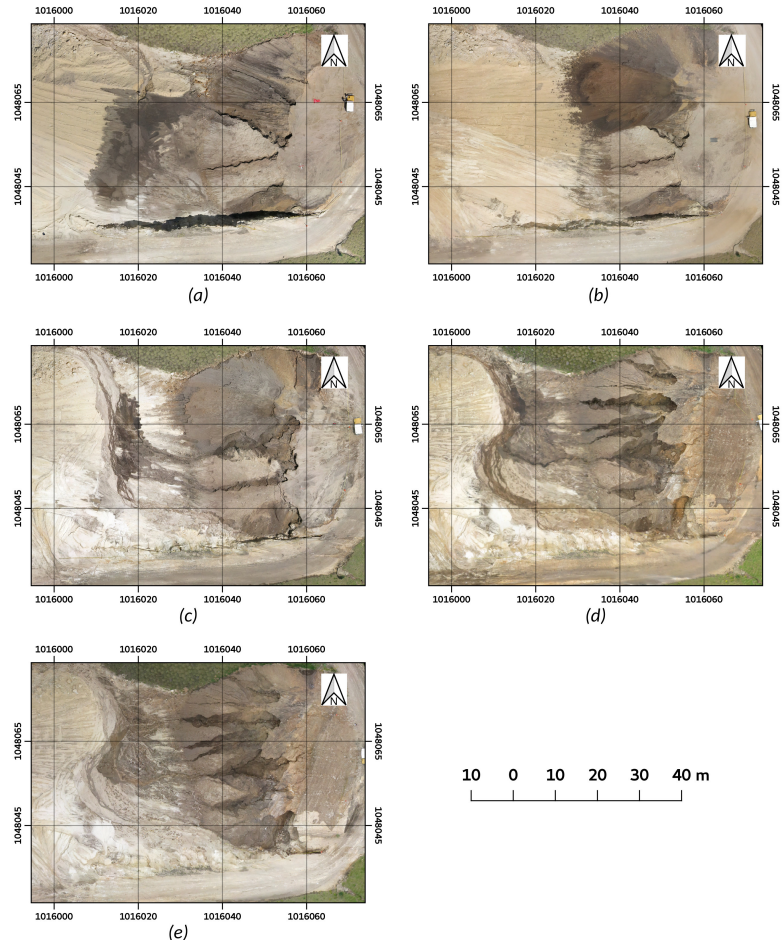

Figure 8. Orthomosaics obtained for all months under study: (a) January; (b) February; (c) March; (d) April; and (e) May.

trast, between the periods of April and May, the changes in the terrain were minimal, this corresponded to a decrease in rainfall intensity mainly in the month of May.
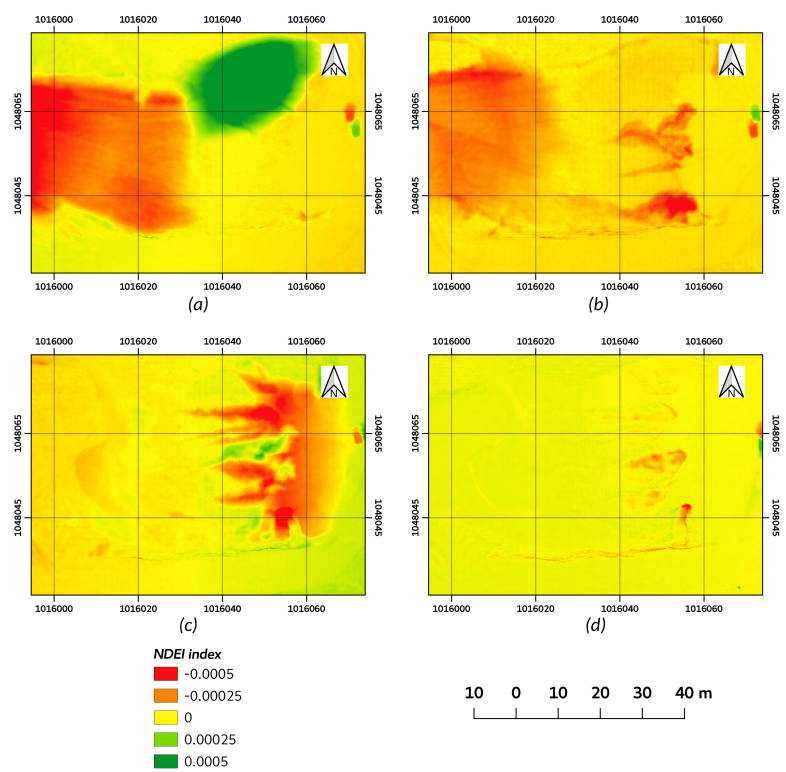

$10 \quad 0 \quad 10 \quad 20 \quad 30 \quad 40 \mathrm{~m}$

Figure 9. NDEI index, land surface changes for time periods under study: (a) January-February; (b) February-March; (c) March-April; and (d) April-May.

Table 1 shows NDEI statistics. It can be noted that the range of NDEI values is higher in the first period, January-February, because of the loss of surface in part of the study area and the deposition of material in other. It is also possible to see that for the periods of large surface change due to rainfalls, FebruaryMarch and March-April, the range of NDEI values expanded 
as well as NDEI mean dropped. This decrease in NDEI mean to suggest that erosion is the main process in those periods. In contrast, in the last period, April-May, the range of NDEI values decreased and the mean value became positive close to 0 as a result of tiny land surface changes.

Table 1. Normalized difference elevation index (NDEI) statistics.

\begin{tabular}{llcccc}
\hline \multirow{2}{*}{} & & NDEI $(\times 100)$ & & & \\
\cline { 3 - 6 } & & Minimum & Maximum & Mean & Standard deviation \\
\hline \multirow{2}{*}{ Period } & January-Fabruary & -0.085 & 0.103 & -0.004 & 0.029 \\
& February-March & -0.081 & 0.032 & -0.011 & 0.010 \\
& March-April & -0.097 & 0.058 & -0.004 & 0.011 \\
& April-May & -0.071 & 0.036 & 0.001 & 0.003 \\
\hline
\end{tabular}

Figure 10, shows detected elevation changes from NDEI: (a) January-February; (b) February-March; (c) March-April; and (d) April-May. NDEI for the months of January and February (Figure 10a) there are no areas affected by runoff but there is a large area of land change, this area corresponds to removal of material carried out by normal mine operations. The area of material deposition is not observed in this image because the method has focused on the detection of erosion zones. The change zones extracted from the index generated for the months of February and March (Figure 10b) shows, in addition to an area of material loss due to mine operations, the appearance of an area of cracks produced by erosion of the land surface caused by heavy rainfall at the end of March. In March and April (Figure 10c) the operations in the study area were minimal so that the change land surface was mainly due to erosion caused by rainfall, so the areas detected of land surface loss correspond only to erosion caused by runoff as well as the sinking of an area contiguous to the cracks. The months of least change, as evidenced in the index, were April and May (Figure 10d), in these months, both normal mine operations in this area and rainfall were minimal so the areas of change detected are small. In this case, the usefulness of using the index is evident, since the task of detecting with the naked eye these changes from the orthomosaics and the DEMs can be a very difficult task.
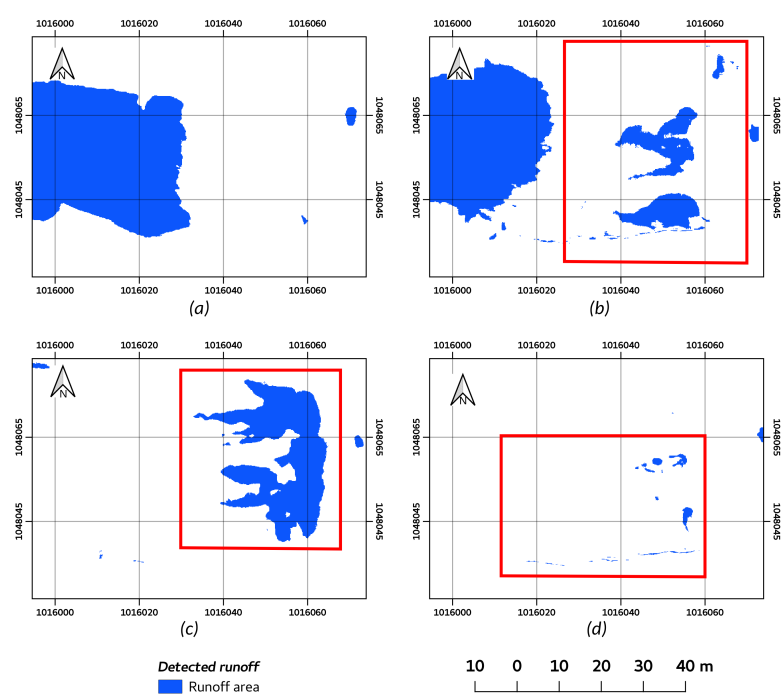

Figure 10. Detected elevation changes from NDEI for time periods under study: (a) January-February; (b) February-March; (c) March-April; and (d) April-May. Surface runoff areas are enclosed by red polygons.

\section{CONCLUSIONS}

The NDEI index can be applied to the analysis of geomorphology in a wide range of time, in our research we analyzed 5 periods with a difference of 30 days, where relevant information was obtained regarding the change of the land surface and the geomorphology changes of the study area, however care must be taken regarding the limitation of the accuracy of digital elevation models. Limitation due to errors and accuracy of the data should be included to improve the analyses proposed in this method.

The proposed method using unmanned aerial vehicles allows for increased spatial and temporal resolution, as well as access to places where fieldwork in remote areas may be unsafe or difficult to perform due to physical barriers. The proposed method is an option for making and understanding geomorphology changes and land surface changes. Studies have shown that multi-temporal monitoring allows risk management with low-cost tools. Using this method allows to have historical data of a great spatial resolution to construct digital models of elevation. Proposed method allows for a rapid mapping of land surface changes as long as it is simple to use and results are easy to depict as well as NDEI index made easy the creation of ranges for interpretation of land surface elevation changes.

\section{ACKNOWLEDGEMENTS}

The authors greatly acknowledge GITUD research group, at Universidad Distrital Francisco Jose de Caldas and SIGA research group at Universidad Nacional de Colombia, for very helpful discussions and comments.

\section{REFERENCES}

Agüera-Vega, F., Carvajal-Ramírez, F., Martínez-Carricondo, P., 2016. Accuracy of digital surface models and orthophotos derived from unmanned aerial vehicle photogrammetry. Journal of Surveying Engineering, 143(2), 04016025.

Bergstrom, K., Lawrence, A. B., Pelissero, A. J., Hammond, L. J., Maro, E., Bunn, H. T., Musiba, C. M., 2019. Highresolution UAV map reveals erosional patterns and changing topography at Isimila, Tanzania.

Borrelli, P., Robinson, D. A., Fleischer, L. R., Lugato, E., Ballabio, C., Alewell, C., Meusburger, K., Modugno, S., Schütt, B., Ferro, V. et al., 2017. An assessment of the global impact of 21 st century land use change on soil erosion. Nature communications, 8(1), 2013.

Chapin, F. S., Sturm, M., Serreze, M. C., McFadden, J., Key, J., Lloyd, A., McGuire, A., Rupp, T., Lynch, A., Schimel, J. P. et al., 2005. Role of land-surface changes in Arctic summer warming. science, 310(5748), 657-660.

Clapuyt, F., Vanacker, V., Van Oost, K., 2016. Reproducibility of UAV-based earth topography reconstructions based on Structure-from-Motion algorithms. Geomorphology, 260, 415.

Cook, K. L., 2017. An evaluation of the effectiveness of lowcost UAVs and structure from motion for geomorphic change detection. Geomorphology, 278, 195-208. 
Erdelj, M., Natalizio, E., 2016. Uav-assisted disaster management: Applications and open issues. 2016 international conference on computing, networking and communications (ICNC), IEEE, $1-5$.

Fugazza, D., Scaioni, M., Corti, M., D’Agata, C., Azzoni, R. S., Cernuschi, M., Smiraglia, C., Adele Diolaiuti, G., 2018. Combination of UAV and terrestrial photogrammetry to assess rapid glacier evolution and map glacier hazards.

Gessesse, B., Bewket, W., Bräuning, A., 2015. Model-based characterization and monitoring of runoff and soil erosion in response to land use/land cover changes in the Modjo watershed, Ethiopia. Land Degradation \& Development, 26(7), 711-724.

Hill, J., Megier, J., Mehl, W., 1995. Land degradation, soil erosion and desertification monitoring in Mediterranean ecosystems. Remote Sensing Reviews, 12(1-2), 107-130.

James, L. A., Hodgson, M. E., Ghoshal, S., Latiolais, M. M., 2012. Geomorphic change detection using historic maps and DEM differencing: The temporal dimension of geospatial analysis. Geomorphology, 137(1), 181-198.

Jenkins, D., Vasigh, B., 2013. The economic impact of unmanned aircraft systems integration in the United States. Association for Unmanned Vehicle Systems International (AUVSI).

LIULeibao, Z. Z. M. L. C., 2019. UAV photogrammetric monitoring of Antarctic ice doline formation. journall, 55(1), 19. http://www.bnujournal.com/EN/abstract/article 1710. shtml.

Lizarazo, I., Angulo, V., Rodríguez, J., 2017. Automatic mapping of land surface elevation changes from UAV-based imagery. International journal of remote sensing, 38(8-10), $2603-$ 2622.

Muchiri, N., Kimathi, S., 2016. A review of applications and potential applications of uav. Proceedings of Sustainable Research and Innovation Conference, 280-283.

Newcome, L. R., 2004. Unmanned aviation: a brief history of unmanned aerial vehicles. American Institute of Aeronautics and Astronautics.

Rossi, P., Mancini, F., Dubbini, M., Mazzone, F., Capra, A., 2017. Combining nadir and oblique UAV imagery to reconstruct quarry topography: Methodology and feasibility analysis. European Journal of Remote Sensing, 50(1), 211-221.

Ruzgienè, B., Berteška, T., Gečyte, S., Jakubauskienè, E., Aksamitauskas, V. Č., 2015. The surface modelling based on UAV Photogrammetry and qualitative estimation. Measurement, 73, 619-627.

Stow, D., Hope, A., Nguyen, A. T., Phinn, S., Benkelman, C. A., 1996. Monitoring detailed land surface changes using an airborne multispectral digital camera system. IEEE Transactions on Geoscience and Remote Sensing, 34(5), 1191-1203.

Uysal, M., Toprak, A., Polat, N., 2015. DEM generation with UAV Photogrammetry and accuracy analysis in Sahitler hill. Measurement, 73, 539-543.

Wannous, C., Velasquez, G., 2017. United nations office for disaster risk reduction (unisdr) - unisdr's contribution to science and technology for disaster risk reduction and the role of the international consortium on landslides (icl). Workshop on World Landslide Forum, Springer, 109-115. 